\title{
Serianthes nelsonii Seed Germination and Seedling Behavior are Minimally Influenced by Chemical and Light Treatment
}

\author{
Thomas E. Marler ${ }^{(\mathbb{D}}$ \\ College of Natural and Applied Sciences, University of Guam, Mangilao, Gu 96923, USA; \\ thomas.marler@gmail.com; Tel.: +1-671-735-2100
}

Received: 20 March 2019; Accepted: 12 April 2019; Published: 16 April 2019

\begin{abstract}
The role of seed imbibition and light during germination are not known for the critically endangered Serianthes nelsonii Merr. Scarified seeds were pre-soaked in gibberellic acid $\left(\mathrm{GA}_{3}\right)$ up to $300 \mathrm{mg} / \mathrm{L}$ and nitrate solutions of $3000 \mathrm{mg} / \mathrm{L}$ to determine if germination was influenced by these treatments. Scarified and imbibed seeds were incubated in high red:far red and low red:far red light to determine the influence of light quality on germination traits. The $\mathrm{GA}_{3}$ and nitrate treatments did not influence germination percentage or timing, but did increase the height of newly emerged seedlings. Moreover, $\mathrm{GA}_{3}$ extended the longevity of cotyledons and shortened the window of time that seedlings required to resume height growth. These growth responses were not sustained, and all seedlings reached heights of $30 \mathrm{~cm}$ at a similar number of weeks. The light treatments did not influence any of the germination response traits. The results indicate that imbibing seeds with chemical solutions and providing light in a range of light quality treatments exerted a minimal influence on S. nelsonii seed germination behaviors. Imbibing seeds with water and germinating in darkness is sufficient for achieving the germination of this endangered tree species.
\end{abstract}

Keywords: endangered species; Guam; imbibition; priming

\section{Introduction}

The seed-to-seedling transition is an important phenological transition and every plant species exhibits a unique suite of requirements for germination and seedling establishment [1-3]. The determination of these requirements is a prerequisite for successfully growing tree species that are important in large-scale horticulture and silviculture. Similarly, the germination requirements for tree species that are threatened with extinction must be known for successful conservation nursery management with limited access to seeds.

Serianthes nelsonii is a critically endangered legume tree species restricted to the islands of Guam and Rota [4]. Thousands of container-grown transplants will be required to fulfill the goals of the published species recovery plan $[5,6]$. Yet germination treatments that maximize the propagation success of this species have been only minimally studied. A single mature tree remains as the sole seed source for Guam's population of S. nelsonii. Even a modest increase in the germination success of this severely limited seed source may benefit species recovery efforts.

The first objective of this study was to determine the influences of nitrogen and gibberellic acid $\left(\mathrm{GA}_{3}\right)$ pre-soak treatments on $S$. nelsonii germination traits. The second objective was to determine the influence of light quality on $S$. nelsonii germination traits. These treatments have been widely used as seed treatments to improve the germination of many plant species. The continued investigation of S. nelsonii seed germination traits may provide important information for improving species recovery. 


\section{Materials and Methods}

Serianthes nelsonii seeds were collected in Guam from May 2013 through January 2014 (Recovery Permit TE-84876A-0) and stored in darkness in ambient conditions. The influence of light and pre-soaking seeds with chemical solutions on seed germination was studied in October 2014 through February 2015. For all treatments, the methods to mitigate physical dormancy followed protocols as previously described [7]. Scarification of the seed coat was accomplished prior to imbibition by opening a small hole at a position that was $90^{\circ}$ from the hilum by scratching on 50-grit sandpaper until cotyledon tissue could be seen beneath the testa. Seeds were subsequently soaked in a $10 \%$ bleach solution for $3 \mathrm{~min}$, then soaked in tap water or chemical solutions for a total of $1 \mathrm{~h}$. The water or solution was decanted and replaced every $15 \mathrm{~min}$ to ensure adequate oxygenation. A fully imbibed seed exhibits greater seed size and the testa becomes less dark and wrinkled (Figure 1a).

Each experimental unit consisted of five imbibed seeds which were sandwiched within wet paper towels and placed in $18 \times 19 \mathrm{~cm}$ plastic ziploc bags. Germination was checked every $12 \mathrm{~h}$ and the paper towels were re-moistened if needed. A seed was recorded as germinated when the radicle reached $1 \mathrm{~mm}$ in length, and was removed from the incubation bags immediately upon germination. Germination for each replication continued until every seed germinated or when un-germinated seeds were unmistakably dead. Seeds of this species that do not germinate have an unambiguous appearance and odor.

Germinated seeds were planted individually in $0.625 \mathrm{~L}$ containers using a $60 \%$ peat and $40 \%$ perlite medium. The plants were placed under $45 \%$ sunlight transmission and grown as previously described [8]. The initial growth phase of S. nelsonii seedlings includes the full extension of the hypocotyl, retention of the cotyledons, full extension of one internode above the cotyledons, and the expansion of an opposite pair of bi-pinnately compound leaves [5]. Following this, a quiescent stage occurs for several days during which no stem extension is observed (Figure 1b). When resumption of seedling height growth commences, the stem growth is continuous, and the pinnately compound leaves are borne with an alternate arrangement and become larger and more complex with height. At the end of the germination growth phase, the length of the hypocotyl and epicotyl were measured for each seedling. Each seedling was subsequently observed daily to record when both cotyledons had abscised, then when growth resumption of the stem occurred following the quiescent period. The seedlings were grown until they reached a height of $30 \mathrm{~cm}$ (Figure 1c). The number of weeks required to reach this height was recorded for each seedling.

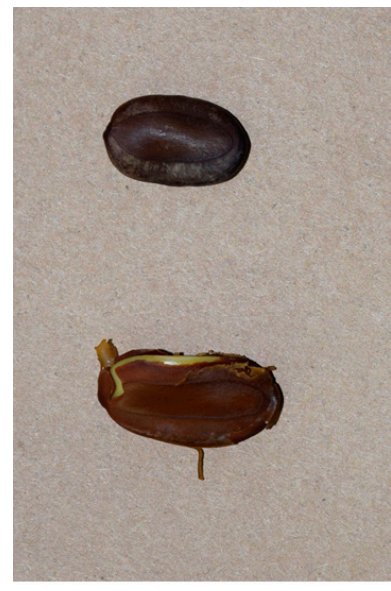

(a)

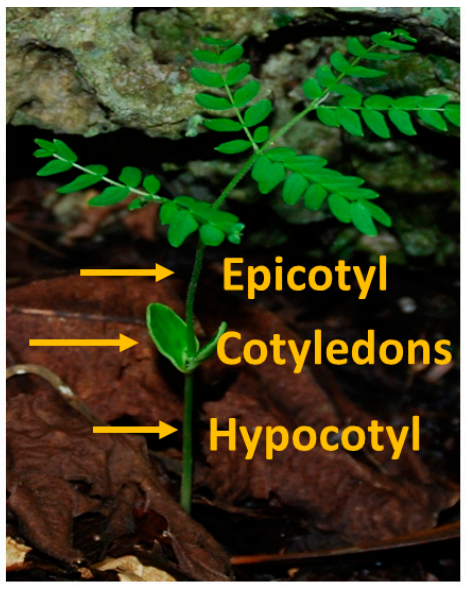

(b)

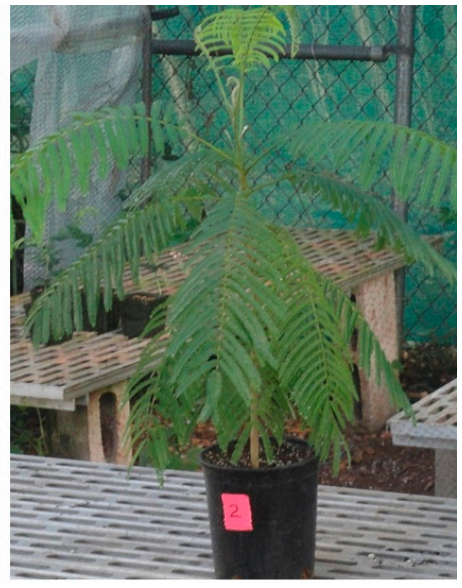

(c)

Figure 1. The general appearance of a Serianthes nelsonii seedling. (a) Non-scarified seed (top) and scarified + imbibed seed (bottom). (b) At the end of the germination growth phase when a quiescent period occurs. (c) General appearance at about $30 \mathrm{~cm}$ height. 


\subsection{Light Methods}

The influence of light quality on seed germination was studied using two protocols. First, incandescent bulbs were employed to provide a low red:far red (R:FR) light of 0.7 at a photon flux density (PFD) of $60 \mu \mathrm{mol} / \mathrm{m}^{2} / \mathrm{s}$. A Skye SKP200 quantum sensor (Skye Instruments, Llandrindod Wells, Powys, UK) was used to quantify PFD, and a Skye SKR110 R:FR sensor was used to determine incident R:FR for each of the treatments. Fluorescent bulbs were used to provide a high R:FR light of 4.8 at the same PFD. Second, incident sunlight was intercepted by a fresh leaf of Ochrosia oppositifolia (Lam.) K. Schum. to provide a low R:FR of transmitted light. The leaf was placed on top of the incubation bag and replaced twice per day to ensure the quality of transmitted light was not altered by leaf desiccation. The R:FR was $0.21 \pm 0.3$ and the PFD was $64 \mu \mathrm{mol} / \mathrm{m}^{2} / \mathrm{s}$. Incident sunlight was intercepted by neutral density shade fabric to provide a high R:FR of transmitted light. The R:FR was $1.14 \pm 0.01$ and the PFD was $61 \mu \mathrm{mol} / \mathrm{m}^{2} / \mathrm{s}$. For both trials, a dark treatment was also included. For all batches incubated in darkness, the daily check for germination occurred under indirect light from a low wattage incandescent bulb. The amount of light was below the detection limits of the quantum sensor. A high-low recording thermometer was used to quantify temperature. The mean low temperature was $28.7^{\circ} \mathrm{C}$ and the mean high temperature was $30.7^{\circ} \mathrm{C}$. Seeds were scarified and imbibed with water for $1 \mathrm{~h}$ prior to placing in the wet paper towels to begin the incubations.

\subsection{Chemical Pre-Soak Methods}

Two approaches were employed to study $1 \mathrm{~h}$ of imbibition of $S$. nelsonii seeds with chemical solutions. First, two forms of nitrate were used at $3000 \mathrm{mg} / \mathrm{L}$ to determine if a nitrogen solution influenced germination traits, based on the upper end of the range that is recommended for germination tests $[9,10]$. The treatments were $\mathrm{NH}_{4} \mathrm{NO}_{3}(37.5 \mathrm{mM}), \mathrm{KNO}_{3}(29.7 \mathrm{mM})$ and a water control. The mean low temperature was $29.1^{\circ} \mathrm{C}$ and the mean high temperature was $31.1^{\circ} \mathrm{C}$. The incubations occurred in darkness. Second, five dose levels of $\mathrm{GA}_{3}$ were used to determine if this hormone influenced germination traits. The doses were $0,50,100,200$, or $300 \mathrm{mg} / \mathrm{L}(0,0.14,0.29,0.58$, or $0.67 \mathrm{mM}$, respectively). The mean low temperature was $28.5^{\circ} \mathrm{C}$ and the mean high temperature was $30.9^{\circ} \mathrm{C}$. The incubations occurred in darkness.

\subsection{Statistics}

The germination and seedling response variables within each trial were subjected to a one-way ANOVA (SAS 9.3; SAS Institute, Cary, NC, USA). For response variables that were significantly influenced by nitrate or light treatments, mean separation was significantly different at $p=0.05$. For response variables that were significantly influenced by $\mathrm{GA}_{3}$ dose level, linear and quadratic functions were fitted to the data using the PROC GLM statement in SAS 9.3.

\section{Results and Discussion}

\subsection{Light Treatments}

Light quality as supplied by light bulbs with contrasting R:FR traits did not influence any of the response variables in this study (Table 1). The mean germination for this trial was $68.9 \%$, the number of days for both cotyledons to abscise was $8.6 \mathrm{~d}$, the number of days for growth resumption to occur was $8.4 \mathrm{~d}$, and these seedlings reached a height of $30 \mathrm{~cm}$ in $17.3 \mathrm{w}$.

Light quality as supplied by blocking sunlight transmission with a live leaf or with shade cloth did not influence any of the response variables in this study (Table 2). The mean germination for this trial was $72.2 \%$, the number of days for both cotyledons to abscise was $8.5 \mathrm{~d}$, the number of days for growth resumption to occur was $8.1 \mathrm{~d}$, and these seedlings reached a height of $30 \mathrm{~cm}$ in $17.3 \mathrm{w}$. 
Table 1. The influence of exposing germinating Serianthes nelsonii seeds to darkness or light of $60 \mu \mathrm{mol} / \mathrm{m}^{2} / \mathrm{s}$ as low red:far red light (0.7; incandescent bulb) or high red:far red light (4.8; fluorescent bulb) on germination and seedling traits. Mean \pm standard error. Six replications, five seeds each.

\begin{tabular}{ccccccc}
\hline Response Variable & Darkness & Incandescent & Fluorescent & Mean & $\boldsymbol{F}$ & $p$ \\
\hline Germination (\%) & $70.0 \pm 4.5$ & $66.7 \pm 4.2$ & $70.0 \pm 4.5$ & 68.9 & 0.1923 & 0.8271 \\
Initial germination (h) & $42.0 \pm 2.7$ & $44.0 \pm 4.0$ & $38.0 \pm 2.0$ & 41.3 & 1.0294 & 0.3811 \\
Final germination (h) & $58.0 \pm 2.0$ & $58.0 \pm 2.0$ & $54.0 \pm 2.7$ & 56.7 & 1.0526 & 0.3734 \\
Germination duration (h) & $16.0 \pm 4.0$ & $16.0 \pm 4.0$ & $14.0 \pm 4.8$ & 15.3 & 0.0725 & 0.9304 \\
Hypocotyl length (mm) & $22.8 \pm 1.7$ & $22.2 \pm 2.1$ & $19.8 \pm 1.6$ & 21.6 & 1.0038 & 0.3898 \\
Epicotyl length (mm) & $15.7 \pm 1.2$ & $16.3 \pm 1.7$ & $16.2 \pm 1.3$ & 16.1 & 0.0590 & 0.9429 \\
Cotyledon death (d) & $8.3 \pm 0.7$ & $8.7 \pm 0.6$ & $8.8 \pm 0.6$ & 8.6 & 0.1977 & 0.8227 \\
Growth resumption (d) & $8.7 \pm 0.6$ & $8.3 \pm 0.8$ & $8.2 \pm 0.6$ & 8.4 & 0.1643 & 0.8499 \\
Time to 30-cm height (w) & $17.3 \pm 0.6$ & $16.8 \pm 0.9$ & $17.8 \pm 0.9$ & 17.3 & 0.2848 & 0.7561 \\
\hline
\end{tabular}

Table 2. The influence of exposing germinating Serianthes nelsonii seeds to darkness, low red:far red light of $64 \mu \mathrm{mol} / \mathrm{m}^{2} / \mathrm{s}\left(0.21\right.$; shade by Ochrosia oppositifolia leaf), or high red:far red light of $61 \mu \mathrm{mol} / \mathrm{m}^{2} / \mathrm{s}$ (1.14; shade by cloth) on germination and seedling traits. Mean \pm standard error. Six replications, five seeds each.

\begin{tabular}{ccccccc}
\hline Response Variable & Darkness & Leaf Shade & Cloth Shade & Mean & $\boldsymbol{F}$ & $p$ \\
\hline Germination (\%) & $73.3 \pm 4.2$ & $70.0 \pm 4.5$ & $73.3 \pm 4.2$ & 72.2 & 1.5513 & 0.2441 \\
Initial germination (h) & $38.0 \pm 2.0$ & $38.0 \pm 2.0$ & $38.0 \pm 2.0$ & 38.0 & 0 & 1.0000 \\
Final germination (h) & $52.0 \pm 4.0$ & $52.0 \pm 4.0$ & $56.0 \pm 2.5$ & 53.3 & 0.4617 & 0.6666 \\
Germination duration (h) & $14.0 \pm 4.8$ & $14.0 \pm 4.8$ & $18.0 \pm 2.7$ & 15.3 & 0.2985 & 0.7462 \\
Hypocotyl length (mm) & $22.7 \pm 1.8$ & $22.2 \pm 2.0$ & $20.8 \pm 1.9$ & 21.8 & 0.2503 & 0.7818 \\
Epicotyl length (mm) & $16.3 \pm 1.8$ & $16.0 \pm 1.1$ & $16.2 \pm 1.9$ & 16.2 & 0.0145 & 0.9856 \\
Cotyledon death (d) & $8.7 \pm 0.8$ & $8.3 \pm 0.6$ & $8.5 \pm 0.5$ & 8.5 & 0.0664 & 0.9361 \\
Growth resumption (d) & $8.2 \pm 0.7$ & $7.7 \pm 0.7$ & $8.3 \pm 0.8$ & 8.1 & 0.2490 & 0.7827 \\
Time to 30-cm height (w) & $17.5 \pm 1.5$ & $17.0 \pm 1.3$ & $17.3 \pm 0.9$ & 17.3 & 0.0426 & 0.9584 \\
\hline
\end{tabular}

\subsection{Nitrogen Treatments}

Pre-soaking $S$. nelsonii seeds with nitrate solutions did not influence germination percentage, the time required for the first seed to germinate, the time required for all of the seeds to germinate, or the duration of germination (Table 3). The mean germination for this trial was 76.7\%. Hypocotyl and epicotyl lengths were increased by both nitrate sources above that of the water control. The number of days for both cotyledons to abscise was $8.4 \mathrm{~d}$, and was not influenced by the nitrate treatments. The number of days for growth resumption to occur was $10.4 \mathrm{~d}$, and was not influenced by the nitrate treatments. These seedlings reached a height of $30 \mathrm{~cm}$ in $16.4 \mathrm{w}$, and the pre-soak with nitrate solutions did not influence this response variable.

Table 3. The influence of imbibing Serianthes nelsonii seeds with water or $3000 \mathrm{mg} / \mathrm{L}$ ammonium nitrate or potassium nitrate on germination in darkness and seedling traits. Mean \pm standard error. Six replications, five seeds each.

\begin{tabular}{|c|c|c|c|c|c|}
\hline Response Variable & Water & $\mathrm{NH}_{4} \mathrm{NO}_{3}$ & $\mathrm{KNO}_{3}$ & $F$ & $p$ \\
\hline Germination (\%) & $73.3 \pm 6.7$ & $76.7 \pm 6.1$ & $80.0 \pm 5.2$ & 0.3061 & 0.7408 \\
\hline Initial germination $(\mathrm{h})$ & $46.0 \pm 2.0$ & $44.0 \pm 2.5$ & $46.0 \pm 2.0$ & 0.6919 & 0.5159 \\
\hline Final germination (h) & $62.0 \pm 2.0$ & $62.0 \pm 2.0$ & $62.0 \pm 2.0$ & 0 & 1.0000 \\
\hline Germination duration (h) & $16.0 \pm 4.0$ & $18.0 \pm 4.1$ & $16.0 \pm 2.5$ & 0.1020 & 0.9036 \\
\hline Hypocotyl length (mm) & $21.5 \pm 0.9 \mathrm{a}^{1}$ & $26.5 \pm 1.3 b$ & $27.2 \pm 1.2 b$ & 6.8609 & 0.0077 \\
\hline Epicotyl length (mm) & $16.2 \pm 0.5 a$ & $20.0 \pm 0.3 b$ & $19.8 \pm 0.3 b$ & 12.5495 & 0.0006 \\
\hline Cotyledon death $(\mathrm{d})$ & $8.3 \pm 0.8$ & $7.8 \pm 0.7$ & $9.1 \pm 0.8$ & 0.5490 & 0.5887 \\
\hline Growth resumption $(\mathrm{d})$ & $9.8 \pm 0.7$ & $10.3 \pm 0.6$ & $11.0 \pm 0.6$ & 0.7312 & 0.4977 \\
\hline Time to $30-\mathrm{cm}$ height (w) & $16.3 \pm 0.4$ & $16.5 \pm 0.6$ & $16.3 \pm 0.4$ & 0.0376 & 0.9632 \\
\hline
\end{tabular}

\footnotetext{
${ }^{1}$ Means followed by the same letter within each row are not different according to least significant difference.
} 


\subsection{Gibberellic Acid Treatments}

Imbibing $S$. nelsonii seeds with $\mathrm{GA}_{3}$ solutions did not influence the germination percentage, the time required for the first seed to germinate, the time required for all of the seeds to germinate, or the duration of germination (Table 4). Mean germination for this trial was $76.7 \%$. A linear increase in hypocotyl length occurred in response to the $\mathrm{GA}_{3}$ dose level, but epicotyl length was not influenced. The number of days for both cotyledons to abscise increased in a linear pattern with increased $\mathrm{GA}_{3}$ concentration, with the plants receiving $\mathrm{GA}_{3}$ at $300 \mathrm{mg} / \mathrm{L}$ exhibiting retention of cotyledons $30 \%$ longer than the control plants. The number of days for growth resumption to occur was reduced by $\mathrm{GA}_{3}$, with the plants receiving $\mathrm{GA}_{3}$ at $300 \mathrm{mg} / \mathrm{L}$ exhibiting a 33\% reduction in the number of days for resumption as compared to the control plants. These seedlings reached a height of $30 \mathrm{~cm}$ in $16.7 \mathrm{w}$, and the $\mathrm{GA}_{3}$ treatments did not influence this response variable.

Table 4. The influence of imbibing Serianthes nelsonii seeds with gibberellic acid $\left(\mathrm{mg} / \mathrm{L} \mathrm{GA}_{3}\right)$ on germination in darkness and seedling traits. Mean \pm standard error. Six replications, five seeds each.

\begin{tabular}{|c|c|c|c|c|c|c|}
\hline Response Variable & 0 & 50 & 100 & 200 & 300 & Significance $^{1}$ \\
\hline Germination (\%) & $76.7 \pm 6.1$ & $73.3 \pm 4.2$ & $73.3 \pm 6.7$ & $76.7 \pm 3.3$ & $83.3 \pm 6.1$ & NS \\
\hline Initial germination $(\mathrm{h})$ & $46.0 \pm 2.0$ & $44.0 \pm 2.5$ & $46.0 \pm 2.0$ & $46.0 \pm 2.0$ & $46.0 \pm 2.0$ & NS \\
\hline Final germination (h) & $62.0 \pm 2.0$ & $62.0 \pm 2.0$ & $62.0 \pm 2.0$ & $62.0 \pm 2.0$ & $62.0 \pm 2.0$ & NS \\
\hline Germination duration (h) & $16.0 \pm 4.0$ & $16.0 \pm 3.0$ & $16.0 \pm 2.5$ & $16.0 \pm 2.5$ & $16.0 \pm 2.5$ & NS \\
\hline Hypocotyl length (mm) & $23.3 \pm 1.8$ & $26.2 \pm 1.9$ & $28.7 \pm 1.2$ & $29.2 \pm 1.4$ & $33.8 \pm 2.7$ & $\mathrm{~L}^{* * *}$ \\
\hline Epicotyl length (mm) & $16.2 \pm 1.8$ & $16.3 \pm 1.4$ & $16.5 \pm 1.8$ & $16.3 \pm 1.8$ & $16.2 \pm 1.9$ & NS \\
\hline Cotyledon death (d) & $8.2 \pm 0.6$ & $8.8 \pm 0.5$ & $9.8 \pm 0.5$ & $10.2 \pm 0.5$ & $10.7 \pm 0.4$ & $\mathrm{~L}^{* * *}$ \\
\hline Growth resumption (d) & $10.7 \pm 0.3$ & $8.5 \pm 0.4$ & $7.8 \pm 0.6$ & $7.3 \pm 0.5$ & $7.2 \pm 0.4$ & $\mathrm{~L}^{* * *} \mathrm{Q}^{* *}$ \\
\hline Time to $30-\mathrm{cm}$ height (w) & $16.7 \pm 1.0$ & $17.0 \pm 1.0$ & $16.7 \pm 0.8$ & $16.0 \pm 1.1$ & $17.3 \pm 0.8$ & NS \\
\hline
\end{tabular}

${ }^{1} \mathrm{NS}=$ not significant. $\mathrm{L}=$ linear. $\mathrm{Q}=$ quadratic. ${ }^{* *} p<0.01 .{ }^{* * *} p<0.001$.

\subsection{Interpretations}

The Recovery Plan for Serianthes nelsonii [6] called for more research, and my results contribute to that component of species recovery. Seed imbibition with various ionic, hormonal, or osmotic solutions is a successful technique for the increasing seed germination percentage, increasing the speed of germination, and improving seedling establishment [11,12]. Heydecker [13] was influential in first describing the benefits of the technique. Herein, imbibition of S. nelsonii seeds with various solutions exerted minimal influence on the germination traits that were measured. The significant changes in initial seedling height and the speed of seedling growth were ephemeral. The use of hormone solutions for priming seeds may mitigate some of the detrimental effects of abiotic stressors on seed germination [14]. My germination trials were conducted in the absence of abiotic stress. Therefore, the influence of $\mathrm{GA}_{3}$ on $\mathrm{S}$. nelsonii germination traits may be more profound under stressful conditions.

Various forms of GA may induce contrasting plant responses in bioassays and efficacy may differ among the plant species being studied. The influence of $\mathrm{GA}_{3}$ on germination and seedling behavior has been shown to promote hypocotyl and early stem growth of other species [15-17] which corroborates my findings with S. nelsonii. Commercially available $\mathrm{GA}_{4+7}$ is available for seed treatments, and further study with this and other forms of GA may greatly improve the germination protocols for S. nelsonii.

Light quantity and quality are environmental factors that influence the seed germination of some species [18-21]. The red:far red ratio is an effective cue that plants use to detect the potential for future shading [22]. Red enriched light is characteristic of forest conditions where gaps or large sunflecks reach the forest floor. Far-red enriched light is characteristic of forest conditions with a closed, dense canopy. In this study, exposing the S. nelsonii seeds to various light quality conditions during incubation exerted minimal influence on the germination traits that were measured.

These results lend evidence to the assertion that the seed-to-seedling stage is not a limiting factor for the regeneration of S. nelsonii. When the testa was broken and imbibition was initiated, germination was rapid regardless of chemical pre-soak or light treatments during incubation. The longevity of the in 
situ seedlings was severely constrained [23], and greater efforts are needed to more fully understand the constraints on the seedling-to-sapling stage. For example, in species such as $S$. nelsonii that germinate in deep shade within a late climax forest community, shade tolerance is required for adequate initial seedling survival. Understanding the lower limits of shade that $S$. nelsonii seedlings can tolerate is an agenda that should be pursued.

\subsection{Conclusions}

Serianthes nelsonii seeds were minimally responsive to pre-soaking in $\mathrm{GA}_{3}$ or nitrate solutions, indicating that imbibition treatments are likely not important for improving the germination traits of this species. Serianthes nelsonii seeds were not responsive to R:FR light treatments during germination incubation, indicating that the germination of seeds for this tree species is light-independent. The general lack of change in seed germination behavior among an extensive range of seed treatments indicates that the germination stage is not likely a limitation to the regeneration of $S$. nelsonii under natural conditions and the provision of testa scarification and pre-sowing imbibition with water is fully adequate for germination success.

Funding: This research received no external funding.

Acknowledgments: No take or collection was directly associated with this study. Experimental plans and results approved by the Environmental Flight, Andersen Air Force Base. Nursery support was provided by Nirmala Dongol and Cameron Musser.

Conflicts of Interest: The author declares no conflict of interest. The founding sponsors had no role in the design of the study; in the collection, analyses, or interpretation of data; in the writing of the manuscript, and in the decision to publish the results.

\section{References}

1. Harper, J.L. Population Biology of Plants; Academic Press: London, UK, 1977; ISBN 0-12-325850-2.

2. Baskin, C.C.; Baskin, J.M. Seeds: Ecology, Biogeography, and Evolution of Dormancy and Germination; Academic Press: San Diego, CA, USA, 1998; ISBN 0-12-080260.

3. Baskin, J.M.; Baskin, C.C.; Li, X. Taxonomy, anatomy and evolution of physical dormancy in seeds. Plant Spec. Biol. 2000, 15, 139-152. [CrossRef]

4. Wiles, G.; Williams, E. Serianthes Nelsonii. The IUCN Red List of Threatened Species. 2017. Available online: https://www.iucnredlist.org/pdflink.98715973 (accessed on 10 March 2019).

5. Marler, T.E. Asexual reproduction to propel recovery efforts of the critically endangered Håyun Lågu tree (Serianthes nelsonii Merr.). Trop. Conserv. Sci. 2017, 10. [CrossRef]

6. United States Fish and Wildlife Services. Recovery Plan for Serianthes nelsonii; United States Fish and Wildlife Services: Portland, OR, USA, 1994.

7. Marler, T.E.; Cascasan, A.N.; Lawrence, J.H. Threatened native trees in Guam: Short-term seed storage and shade conditions influence emergence and growth of seedlings. HortScience 2015, 50, 1049-1054. [CrossRef]

8. Marler, T.; Musser, C. Chemical and air pruning of roots influence posttransplant root traits of the critically endangered Serianthes nelsonii. Plant Root 2016, 10, 21-25. [CrossRef]

9. Basra, A.S. Seed Quality Basic Mechanism and Agricultural Implications; Food Products Press: New York, NY, USA, 1995; ISBN 1-56022-850-4.

10. Copeland, L.O.; McDonald, M.B. Principles of Seed Science and Technology, 4th ed.; Kluwer Academic Publishers: Norwell, MA, USA, 2001; ISBN 978-0792373223.

11. Parera, C.A.; Cantliffe, D.J. Presowing seed priming. In Horticultural Reviews; Janick, J., Ed.; John Wiley \& Sons, Inc.: Hoboken, NJ, USA, 2010; pp. 109-141. [CrossRef]

12. Yadav, R.K.; Saini, P.K.; Pratap, M.; Tripathi, S.K. Techniques of seed priming in field crops. Int. J. Chem. Stud. 2018, 6, 1588-1594.

13. Heydecker, W. Accelerated germination by osmotic seed treatment. Nature 1973, 246, 42-44. [CrossRef]

14. Nimir, N.E.A.; Lu, S.; Zhou, G.; Guo, W.; Ma, B.; Wang, Y. Comparative effects of gibberellic acid, kinetin and salicylic acid on emergence, seedling growth and the antioxidant defence system of sweet sorghum (Sorghum bicolor) under salinity and temperature stresses. Crop Pasture Sci. 2015, 66, 145-157. [CrossRef] 
15. Brian, P.W.; Hemming, H.G. Promotion of cucumber hypocotyl growth by two new gibberellins. Nature 1961, 189, 74. [CrossRef]

16. Crozier, A.; Kuo, C.C.; Durley, R.C.; Pharis, R.P. The biological activities of 26 gibberellins in nine plant bioassays. Can. J. Bot. 1970, 48, 867-877. [CrossRef]

17. Derkx, M.P.M.; Vermeer, E.; Karssen, C.M. Gibberellins in seeds of Arabidopsis thaliana: Biological activities, identification and effects of light and chilling on endogenous levels. Plant Growth Regul. 1994, 15, 223-234. [CrossRef]

18. Bewley, J.D. Seed germination and dormancy. Plant Cell 1997, 9, 1055-1066. [CrossRef] [PubMed]

19. Shinomura, T. Phytochrome regulation of seed germination. J. Plant Res. 1997, 110, 151-161. [CrossRef] [PubMed]

20. Pons, T.L. Seed responses to light. In Seed: The Ecology of Regeneration in Plant Communities; Fenner, M., Ed.; CABI Publishing: New York, NY, USA, 2000; pp. 237-260.

21. Vayda, K.; Donohue, K.; Auge, G.A. Within- and trans-generational plasticity: Seed germination responses to light quantity and quality. AoB Plants 2018, 10, ply023. [CrossRef] [PubMed]

22. Ballaré, C.L.; Scopel, A.L.; Sanchez, R.A. Far-red radiation reflected from adjacent leaves: An early signal of competition in plant canopies. Science 1990, 247, 329-332. [CrossRef] [PubMed]

23. Marler, T.E.; Cascasan, A.N. Number of emerged seedlings and seedling longevity of the non-recruiting, Critically Endangered Hayan Lagu tree Serianthes nelsonii Merr. (Fabales: Leguminosae) are influenced by month of emergence. J. Threat. Taxa 2015, 7, 8221-8225. [CrossRef]

(C) 2019 by the author. Licensee MDPI, Basel, Switzerland. This article is an open access article distributed under the terms and conditions of the Creative Commons Attribution (CC BY) license (http://creativecommons.org/licenses/by/4.0/). 